\title{
Utilizing a logic model to identify clinical research problems: a lesson from philosophy of science
}

\author{
This article was published in the following Dove Press journal: \\ Nursing: Research and Reviews \\ II October 2016 \\ Number of times this article has been viewed
}

\section{Cynthia R Collins}

School of Nursing, College of Social Sciences, Loyola University, New Orleans, LA, USA
Correspondence: Cynthia R Collins School of Nursing, College of Social Sciences, Loyola University,

6363 St Charles Ave., New Orleans, LA 70II8, USA

Tel +I 504 304-5659

Email ccollins@loyno.edu; collinsanp@ cox.net

\begin{abstract}
Communication and decision making in the health care workplace often involve finding solutions to ill-structured problems in uncertain, dynamic environments influenced by the competing interests of multiple stakeholders. In this environment, doctoral-prepared nurses who practice as administrators, policy makers, or advanced practice practitioners are often compelled to make important decisions based upon evaluating the merit of colleagues' proposals against some desired organizational or population outcome. Of equal importance is the nurse leader's own capacity to construct a compelling argument or proposal that will drive the organization forward to meet the evolving needs for quality health care. Where do we learn the skills necessary to foster this kind of critical thinking in our professional communications? The author suggests that one teaching-learning approach can be found through the thoughtful application of the work of British philosopher Steven Toulmin. Toulmin defined a model for both the analysis and derivation of logical arguments or proposals that can be readily learned and applied for use in health care systems. This model posits that a substantive argument or claim can be evaluated based on the assumptions it presumes (warrants) and the strength of the evidence base (backing). Several of the social science professions have adapted Toulmin's model to generate analysis and creative solutions to complex or emergent problems. The author proposes that an application of this model be included in the pedagogy of doctoral level Philosophy of Science or Nursing Theory courses. The Toulmin process often provides the doctoral student or novice researcher with their first real learning experience in defining the scope and inherent challenges of framing a clinical issue to be the focus of their scholarly translational projects. Several illustrations, which were eventually researched and further developed for capstone scholarly projects, are presented as exemplars of this process.
\end{abstract}

Keywords: Toulmin, argument, research process, hypothesis formation, nursing education

\section{Introduction}

There has long been a debate among nurse educators of doctoral students regarding the necessity of inclusion of philosophy of science courses in the standard curriculum. ${ }^{1,2}$ The core of scientific knowledge in a discipline is considered to include: concepts of knowledge, an explication of the nature of science, epistemology, scientific validation processes, the history of knowledge formation in the discipline, and theories of reasoning. ${ }^{3}$ Experienced nurse scientists would argue that the derivation of any research question does indeed require an understanding of the philosophy of nursing as a scientific discipline. Historically, university education in the liberal arts was considered incomplete without some introduction to Western philosophical thinking, 
particularly those concepts that explore the analytic tradition of philosophical thought. ${ }^{4}$ Logic as a branch of philosophy, deals in the application of well-justified procedures for reasoning to a conclusion. Facility with the methods of logic is particularly useful in helping graduate students to begin to develop advanced critical thinking skills. The study of the concepts related to logic and logic models can be considered intrinsic to the development of the novice nursing scholar learning to initiate scientific research methods. In the clinical application of logic reasoning, the learner or nurse researcher uses inductive and deductive reasoning skills for both beginning hypothesis formation and confirmation. The initiation of the nursing scholarly process traditionally begins by defining a clinical or systems problem. ${ }^{5}$ The generation of a well-constructed, logical problem statement or argument is a skill that is fundamental to any scholarly project. The intent of this paper is to describe a method for linking the practical application of logical reasoning as taught in a philosophy of science course to the nursing research and scholarship processes required of doctoral students. To this end, Toulmin's Model of Logical Argument ${ }^{6-8}$ has been used as a guide for defining a beginning insightful research problem statement. This method has been successfully incorporated into the curriculum of graduate students enrolled in one Doctor of Nursing Practice (DNP) program, but has implications for application by interdisciplinary students and novice researchers in all of the health and social sciences. The application of logic tools to a variety of problems may well be at the forefront of 21 st-century interdisciplinary knowledge building in the nursing and the health sciences.

\section{Toulmin model}

Twentieth-century British philosopher of science Stephen Toulmin has been credited by nurse theorists as a contributor in the evolution of contemporary nursing science. ${ }^{9-10}$ His work offered a new definition of what comprises a scientific "discipline", allowing for a more distinct role for professional practice within the generation and application of a body of knowledge. Furthermore, he emphasized the necessity of scientific concepts that are not only basic to a discipline, but are also mutually shared among practice disciplines at their conceptual foundations. It is the evolution of these concepts over time, reflection, discourse, and practice that create change in practice disciplines such as nursing and the health sciences.

One conceptual framework that has emerged within the practice of the social and health sciences is that of the necessity for logical appraisal of facts and propositions that may form an evidence base for research, as well as practice. Toulmin constructed a model that can be adapted for use in both the derivation and analysis of logical arguments or problem statements that arise within a practice discipline. Toulmin's original purpose was to deconstruct or analyze the validity of both philosophical and practical arguments by breaking them down into their constituent parts. His approach was based on the concept that rigorous arguments to be effective must present information that can be substantiated and as close to the known truth as possible. Therefore, the argument should be based upon the strongest available evidence that has been demonstrated in the context in which the argument or problem has been derived. ${ }^{6,7}$ This philosophical approach not only resonates today in contemporary legal and political arguments, but has also been adapted for application to the presentation of arguments or problems in the social sciences. ${ }^{11-13}$

The Toulmin model is rooted in a synthesis of concepts derived from inductive reasoning and logic theory. This model posits that a substantive argument (claim) can be evaluated based on the assumptions it presumes (warrants) and the strength of the evidence base (backing). The diagram in Figure 1 illustrates the basic model components, as well as the dynamic interrelationships between these elements.

In the Toulmin model, the "claim" is the statement being argued by the presenter. It usually addresses some issue that is in dispute on which the presenter has taken a stand. This issue could well be the identification of a clinical problem, thesis, or hypothesis. Alternatively, the claim is often a proposed solution to some existing problem in a discipline or practice. The "data", which may also be referred to as the "grounds" in a legal argument, is the empirical evidence that supports the claim. It is usually connected to the claim with the word "because" and is the presenter's justification of, or solution to an argument or problem. The "warrants" are series of logical statements that support a connection between the claim and the initial data. These statements are usually a series of universally accepted beliefs, values, or knowledge held by a discipline or an organization. It is essential to the success of the argument that the audience supports or "buys into" these assumptions; otherwise, there may not be a consensus for the basis of an argument. The "backing" is the body of evidence that allows you to support the truth of a warrant. The backing may include differing levels of evidence such as evidence from previous clinical trials, expert testimony, case history, statistics, rules, or laws. It is also essential that the backing is well documented within the same discipline from which the argument or problem arose. The backing 


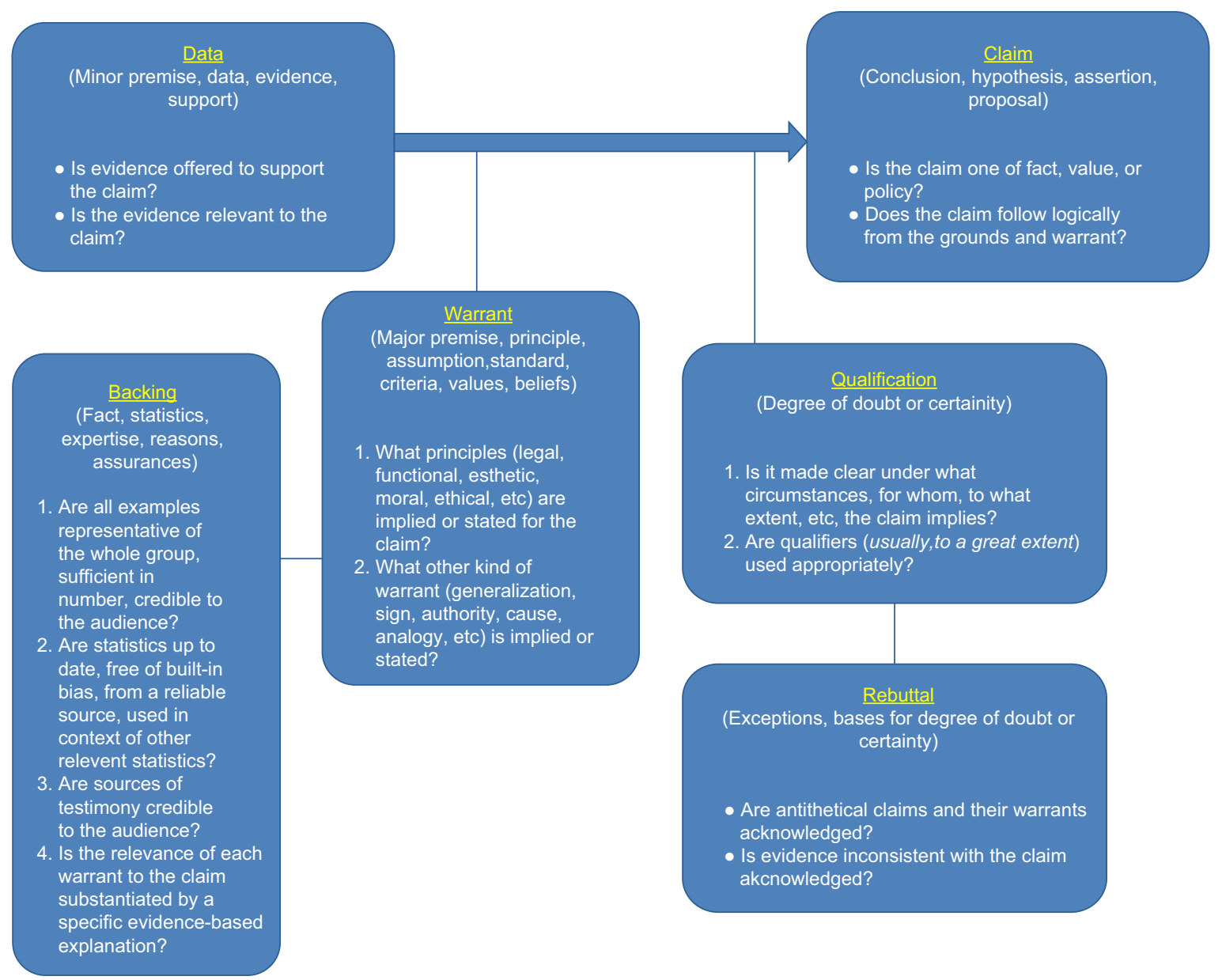

Figure I Toulmin's model of a logic argument ${ }^{6}$ with reflective insights.

further provides evidence to support the warrant, not necessarily the original claim. In this way, the backing represents a step in the process of creating the overall logic and truth of the claim. The more warrants and backing presented in the argument, the stronger the argument will become. Any factual exception to an argument may potentially derail the argument. Therefore, "rebuttals" are anticipated before the argument is presented to the audience. The rebuttals are counterarguments or statements that indicate conditions or situations when the general argument would not hold true. Anticipation of potential rebuttals to the argument permits the presenter to address these discrepancies in advance by qualifying the argument or problem. The "qualifiers" are statements that propose the specific conditions under which the general argument is true..$^{14,15}$

\section{Class exercise}

As one of the assignments in the philosophy of science course, DNP students are required to critically consider a clinical or health care systems problem statement for which they hold a strong opinion as to possible solution. They must construct, label, and analyze these logical arguments accord- ing to Toulmin's model (Table 1). ${ }^{7}$ The argument is further developed into a paper through the students' organization and evaluation of the evidence that they discover in researching the information needed to provide warrants and backing. In a practical way, this exercise accomplishes the following learning outcomes, with regard to the DNP's synthesis of logical thinking: 1) enables systematic deconstruction and analysis of a proposal or argument for its evidence base; 2) creates insight into the "holes" or lack of substantiation in an argument/ proposal; 3) helps one to strengthen an argument/ proposal by anticipating rebuttals/challenges; 4) promotes consideration of counterarguments before an original idea or proposition is presented; and 5) strengthens the DNP's creative synthesis of logical thought to problem-solving behaviors and proposals. ${ }^{11}$

In the first 5 years of the doctoral program, over 80 DNP students have enrolled in the philosophy of science course. These graduate students have constructed many innovative, original logical arguments within the domain of advanced practice health care using this adaptation of the Toulmin model. ${ }^{7}$ The majority of these novice scholars go on to build upon this beginning problem statement to 
Table I Steps in the argument process

I. Statement of the problem

Introduce the claim that will provide the direction for the argument

2. Provide data (initial reasons/evidence) to support the claim

Identify qualifiers that may limit the scope of the argument

3. Suggest warrants that demonstrate a logical connection between the data and the claim

4. Offer supporting facts/statistics as backing to reinforce that the warrants are derived from an evidence base

5. Anticipate rebuttals or counterarguments and specific circumstances where your proposal would not work

6. Research and formulate qualifiers (add to step 2) that would eliminate/limit the impact of anticipated rebuttals

7. Conclusion - summarize the implications of the argument and the resources needed to implement or test the argument, hypothesis, or proposal

create their evidence-based scholarly project required for graduation. In this course, the process derived from the Toulmin model ${ }^{7}$ has been applied to the construction of an argument framework for defining and clarifying a clinical issue or health policy for further study. The following logical argument examples are illustrative of the type of domain-specific arguments that can be derived as a basis for scholarly nursing work:

\section{Example I}

African-American diabetics who have home-based nutrition visits have better outcomes (claim) because the visits are patient-centered and more convenient for the patient (data). Home visits increase diet compliance (warrant), because the visits are usually individualized to the patient's cultural background. Studies suggest that 3.7 million of all nonHispanic blacks, aged 20 years and older, have diagnosed and undiagnosed diabetes (backing).

\section{Example 2}

Health promotion and disease prevention when taught through school programs that promote physical activity, appropriate nutrition education, and general well-being in children have better outcomes for promoting healthy adult lifestyle choices (claim), because providing education on healthy lifestyles during childhood is more effective than trying to make changes as an adult ("School Health Programs: Improving the Health of Our Nation's Youth", 2010) (backing). School health programs are supported by taxes and increase the individual citizen's financial burden (rebuttal). Current health care indices suggest that poor health choices lead to increased use of health care services (backing), which are most frequently used by the uninsured (backing).

\section{Example 3}

Federal disaster medical workers should be trained to care for victims of sexual violence during disaster response efforts (claim) because there is an increase in sexual violence incidents that occur during disasters (data). Post-traumatic stress disorder is a known health response for both disaster and sexual violence victims and negatively impacts long-term health outcomes (warrant). Females are a particularly vulnerable population and experience the highest rate of sexual violence (warrant).

\section{Example 4}

Increasing access to primary health care for all Americans prevents overutilization of Emergency Room (ER) departments for primary care services (claim). The lack of health care access is driving a paradigm shift in the provision of care (warrant). Implementation of the health care bill lies in the hands of the president and Congress (backing). Opponents fear quality of health care will decrease due to the larger numbers of patients covered (rebuttal). Health care access is a matter of social justice for all Americans (warrant, qualification).

\section{Example 5}

Special Operations Forces medical personnel in Afghanistan should refocus their counterinsurgency health care strategy to reflect the most pressing issue for rural Afghan people: maternal infant mortality (claim). Every 27 minutes, an Afghan mother dies from preventable perinatal complications (backing). The Special Operations Forces medical mission is to provide direct care and health education to indigenous people (warrant). This direct care to Afghan females is not sustainable (rebuttal). Special Operations Forces personnel, including NPs, could instruct Afghan medical personnel in pregnancy-related care as a part of their mission (qualifier).

\section{Example 6}

Every minority female should receive education both on breast cancer awareness and breast cancer screening (claim) because providing education and screening to this group of females will decrease the number of deaths from breast cancer in this population (data). Minority females die from breast cancer at higher rates than their Caucasian counterparts (warrant). Minority females are diagnosed at later stages of breast cancer, thus increasing the chances of mortality from breast cancer (backing). 


\section{Example 7}

Mental health services for children and families are inadequate (claim) because of limited access (data). The current mental health system is fragmented (warrant) and the resources to provide care is limited (warrant). A coordinated system of care will help to improve access to services (backing). Improved access to services will improve health outcomes (backing). It will be difficult to coordinate the services of the differing agencies (rebuttal), but the continued research on the successful outcomes of the different systems will assist in providing best practice information for improving the quality of mental health services to children and their families (qualifier).

\section{Example 8}

State governors should accept the Medicaid expansion (claim) because the benefits to the state and its citizens outweigh the costs of the program (data). The governors should want all citizens to have equal access to quality health care (warrant). Only the state governor can accept the Medicaid expansion (backing). With a tight state budget, the states cannot afford to lose the federal incentives to expand the program (backing). The expansion of Medicaid has benefits for patients who are uninsured, providers of uncompensated health care, the state budget, and taxpayers (backing). While the federal government will only pay for new enrollees that fit the guidelines, and only cover $100 \%$ of the costs until 2017, Medicaid expansion will benefit the state in the short run (qualifier).

\section{Example 9}

All nurse practitioners should be able to practice to the full scope of their education and training (claim) because restrictions make it more challenging for patients to access primary health care (data). Fluctuating state laws and/or policies establish boundaries on essentially every aspect of the responsibilities and practice of nurse practitioners (warrant). In 28 states and the District of Columbia, nurse practitioners are regulated by boards of nursing; in the remaining 22 states, nurse practitioners are regulated by boards of medicine (backing). Full practice authority would allow for independence of nurse practitioners and result in meeting the needs of more underserved communities (warrant). Approximately one-third of the nation has adopted full practice authority licensure, which has been shown to greatly increase access and decrease the costs of primary health care (backing). Nurse practitioners would refer all patients with presentations beyond their scope of practice to appropriate medical specialists or physicians (rebuttal).

\section{Example 10}

Diabetic patients have better medical outcomes when primary care is provided by means of the shared medical appointments versus individual office visit (claim) because peer support has been shown to improve metabolic control (data). Shared medical appointments is a conceptual model of care engaging multiple participants uniquely receiving health care and education in a group setting (warrant). Group visits have been shown to increase self-efficacy and self-management of patients with diabetes mellitus (backing). Researchers have reported improved glycemic control, as defined by the American Diabetes Association (backing). The patient should have the autonomous choice of the type of visit that best meets their needs and comfort level (qualifier).

\section{Discussion of learning activity outcomes}

Once they have stated the problem, where does the student go from here? Encouraging the student to transform an observed clinical problem into words on paper is only the beginning of the problem statement. The next step in the process logically leads them to the appropriate literature that will assist the student to discover the existing "state of the science" on that clinical problem and help to approach scientific justification of the problem as an investigative entity worthy of their intervention (Table 1).

This exercise in the philosophy of science course has two observed outcomes: the framework inherent in the Toulmin model provides structure for constructing the argument/problem statement, while at the same time, expression of the problem statement clearly leads the DNP student to examine the problem in the more pragmatic light of the domain-specific science. Students apply the steps in the Toulmin model to secure an evidence base through the identification of backing and warrants that are provided by an initial course-required review of 15-20 evidence-based, peer-reviewed research articles on their topic expressed in the problem statement (as illustrated in the examples cited earlier). Their selection of relevant literature must comprise research that supports the existence of their claim as viable, as well as research work that refutes or provides a counterargument to the claim they have asserted in their problem statement. This process results in the formation and expression of a substantive problem statement that will prepare them to develop their future capstone 
project. As can be seen in the examples cited earlier, the context of the problem constructs have been consistently health systems or patient-centered domain-specific issues. This requires the student to develop a beginning familiarity with the research and existing scientific background in their health care area of interest. An appropriate problem statement combines both the structured elements learned in studying and applying aspects of the Toulmin model for logical argument production, and requires the student to integrate the problem into the more domain-specific nursing setting in which the capstone DNP student practices. Thus, the purpose of this learning activity has supported the assertion that students who have had the philosophy of science course are better prepared to develop and envision a viable, evidence-based scholarly project in their subsequent courses.

There is only one recent study that could be identified in the nursing literature that took these concepts a step further into the clinical environment of a critical care unit (CCU). ${ }^{13}$ In an attempt to categorize elements inherent in the verbal exchanges that occur between CCU nurse during change of shift report, the author suggests that experienced CCU nurses exchange information concerning multiple patient problems and persuasive claims as to the care that needs to be given to those patients through a series brief, staccato statements that combine both the structured elements similar to Toulmin's model, and domain-specific nursing and scientific knowledge. When the format and content of the statements were analyzed for 20 nurse pairs over a 6-month period, it was found that these nurses consistently employed arguments or problem statements that were based on "backing", as described in a process similar to that in the Toulmin model. In other words, the more experienced the nurse the more warrants and data they were able to provide for needed patient interventions. In a very pragmatic way, the professional subjects in this study incorporated domain-specific suggestions and interventions for the care of their patients who adequately reflected the resources, technology, and skills available in the CCU environment. While the course activity presented in this paper has not directly been studied with graduate nurses, this study does suggest that the possibility of teaching nurses to logically identify both structured and domain-specific aspects of health care problems is a type of learning that can be transmitted and continued into clinical practice.

\section{Summary and conclusions}

The study of philosophy of science can provide a useful framework for nursing students to begin to understand the underpinnings of theories and conceptual models that have formed the basis of nursing as a discipline and as a field of inquiry ${ }^{16}$ Emerging evidence and academic discourse support the notion that the transformation of doctoral students into productive nurse scientists requires that they can develop practical applications of philosophic reasoning to the future of scientific inquiry and nursing knowledge. ${ }^{1}$ Doctoral programs present a rich epistemological environment where future nurse researchers and clinically proficient practitioners can acquire the skills and reasoning processes required to read critically, to question extant assumptions, and to discriminate among alternative propositions to advance evidence-based nursing knowledge. ${ }^{17}$

Since the days of Aristotle, philosophers have contended that the pathway to the advancement of knowledge is through an understanding of reasoned facts. ${ }^{18,19}$ This process began with Aristotle's notion of the syllogism. In contemporary philosophy of science, the application of critical thinking models has been attempted in graduate education. Several of the social science professions have adapted Toulmin's model $^{6}$ (particularly the structural emphasis on identification of claims, backings, and warrants) to generate descriptive and normative, domain-specific analyses of the facts and statements presented in logical arguments, problems, or propositions. One fundamental characteristic of a profession is that its knowledge base is constantly evolving. ${ }^{20}$ The aim of contemporary philosophy of science in nursing would do well to transform abstract concepts into ideas that are more accessible for practice. ${ }^{21,22}$ Pedagogy that implements critical thinking skills is essential for future competence and practice in the contemporary milieu of a complex health care environment. In a practice discipline such as nursing, translating knowledge of an intellectual process that can have an immediate impact on a leader's health care decision-making behaviors can serve as a valuable tool for nurse scholars. ${ }^{17}$ The inclusion of this content in a philosophy of science course and graduate practice can engender both insight and leadership skills that empower nurse leaders to employ substantive proposals that persuade others toward needed health care reform. Very few interdisciplinary efforts have been documented that make the concepts inherent in philosophy of science more relevant and useful for students in the science and helping professions. ${ }^{23}$ This paper has described a learning exercise in the philosophy of science course taught in one doctoral program. However, the concepts and processes described here can be easily adapted into the curriculum of most health and social science disciplines.

Research studies designed to measure the extent of improvement in logical/critical thinking associated with the learning model described here will be the next step in the development and application of this pedagogy in the DNP program. 


\section{Disclosure}

The author reports no conflicts of interest in this work.

\section{References}

1. DiBartolo MC. Philosophy of science in doctoral nursing education revisited. J Prof Nurs. 1998;14(6):350-360.

2. Hernandez CA. Student articulation of a nursing philosophical statement: an assignment to enhance critical thinking skills and promote learning. J Nurs Educ. 2009;48(6):343-349.

3. Butts JB, Lundy KS. Teaching philosophy of science in nursing doctoral education. J Nurs Scholarsh. 2003;35(1):87-91.

4. MacIntyre A. God, Philosophy, Universities: A Selective History of the Catholic Philosophical Tradition. Maryland: Rowman \& Littlefield Publishers, Inc.; 2009.

5. Polit DF, Beck CT. Nursing Research: Generating and Assessing Evidence for Nursing Practice, 9th ed. Philadelphia, PA: Wolters Kluwer Health/Lippincott Williams \& Wilkins; 2012.

6. Toulmin S. The Uses of Argument. Cambridge: Cambridge University Press; 1958.

7. Toulmin S. The Uses of Argument (Updated Ed.), Cambridge University Press; 2003.

8. Toulmin S. Rhetorical force of personal argumentation: the recovery of practical philosophy. The American Scholar. 2001.

9. Rodgers BL. Developing Nursing Knowledge: Philosophical Traditions and Influences. Philadelphia, PA: Wolters Kluwer Health/Lippincott Williams \& Wilkins; 2005

10. Toulmin S. Human Understanding (Vol. 1), Princeton, NJ; 1972.
11. Driver R, Newton P, Osborne J. Establishing the norms of scientific argumentation in classrooms. Science. 2000;84(2):403-424.

12. Alison L, Smith M, Eastman O, Rainbow L. Toulmin's philosophy of argument and its relevance to offender profiling. Psychology, Crime and Law. 2003;9(2):173-183.

13. Hagler D, Brem S. Reaching agreement: the structure and pragmatics of critical care nurses' informal argument. Contemp Educ Psychol. 2008;33(3):403-424.

14. Glynn S, Britton BK, Muth D, Dogan N. Writing and revising persuasive documents: cognitive demands. J Educ Psychol. 1982;74(4): 557-567.

15. Britt MA, Larson AA. Constructing representations of arguments. J Mem Lang. 2003;48(4):794-810.

16. Rodriquez T, Kotarba JA. Postmodern philosophies of science: pathways to nursing reality. Southern Online J Nurs Res. 2009;9(1);1-5.

17. Giuliano KK. Expanding the use of empiricism in nursing: can we bridge the gap between knowledge and clinical practice? Nurs Philos. 2003;4(1):44-52.

18. Byrne PH. Analysis and Science in Aristotle. Albany, NY: State University of New York Press; 1997.

19. Whelton B. Nursing as a practical science: some insights from classical Aristotelian science. Nurs Philos. 2000;1:57-63.

20. Reed PG, Lawrence LA. A paradigm for the production of practicebased knowledge. J Nurs Manag. 2008;16(4):422-432.

21. McGee G. (Editorial) Will bioethics take the life of philosophy? Am J Bioeth. 2006;6(5):1-2.

22. Sellman D. Editorial. Nurs Philos. 2008;9(3):151-153.

23. Kourany JA. Getting philosophy of science socially connected. Philos Sci. 2006;73:991-1002.
Nursing: Research and Reviews

\section{Publish your work in this journal}

Nursing: Research and Reviews is an international, peer-reviewed, open access journal publishing original research, reports, reviews and commentaries on all aspects of nursing and patient care. These include patient education and counseling, ethics, management and organizational issues, diagnostics and prescribing, health outcomes, economics and

\section{Dovepress}

resource management, improving patient safety in all settings. The manuscript management system is completely online and includes a very quick and fair peer-review system. Visit http://www.dovepress. com/testimonials.php to read real quotes from published authors. 